\title{
The HUNT study: participation is associated with survival and depends on socioeconomic status, diseases and symptoms
}

\author{
Arnulf Langhammer ${ }^{1 *}$, Steinar Krokstad ${ }^{1}$, Pål Romundstad ${ }^{2}$, Jon Heggland ${ }^{1}$ and Jostein Holmen ${ }^{1}$
}

\begin{abstract}
Background: Population based studies are important for prevalence, incidence and association studies, but their external validity might be threatened by decreasing participation rates. The 50807 participants in the third survey of the HUNT Study (HUNT3, 2006-08), represented 54\% of the invited, necessitating a nonparticipation study.

Methods: Questionnaire data from HUNT3 were compared with data collected from several sources: a short questionnaire to nonparticipants, anonymous data on specific diagnoses and prescribed medication extracted from randomly selected general practices, registry data from Statistics Norway on socioeconomic factors and mortality, and from the Norwegian Prescription Database on drug consumption.

Results: Participation rates for HUNT3 depended on age, sex and type of symptoms and diseases, but only small changes were found in the overall prevalence estimates when including data from 6922 nonparticipants. Among nonparticipants, the prevalences of cardiovascular diseases, diabetes mellitus and psychiatric disorders were higher both in nonparticipant data and data extracted from general practice, compared to that reported by participants, whilst the opposite pattern was found, at least among persons younger than 80 years, for urine incontinence, musculoskeletal pain and headache. Registry data showed that the nonparticipants had lower socioeconomic status and a higher mortality than participants.

Conclusion: Nonparticipants had lower socioeconomic status, higher mortality and showed higher prevalences of several chronic diseases, whilst opposite patterns were found for common problems like musculoskeletal pain, urine incontinence and headache. The impact on associations should be analyzed for each diagnosis, and data making such analyses possible are provided in the present paper.
\end{abstract}

Keywords: Epidemiologic studies, Participation rate, Validity, Selection bias, Mortality

\section{Background}

Population based studies are pivotal for knowledge on health related behavior, prevalence and incidence of symptoms, diseases and death, as well as for assessing potential causal associations in the population. The validity of incidence and prevalence studies rely on the sample of study participants being representative of the actual population, and if participation is influenced by exposures and diseases under study, this may also bias association studies.

\footnotetext{
* Correspondence: arnulf.langhammer@ntnu.no

${ }^{1}$ HUNT Research Centre, Department of Public Health and General Practice, Norwegian University of Science and Technology, Levanger, Norway Full list of author information is available at the end of the article
}

Participation rates in population-based studies have declined during the last three decades [1], and this is the case also in most Norwegian epidemiological studies such as the Nord-Trøndelag Health Study (HUNT) [2-4], the Hordaland Health Study [5] and The Oslo Health Study [6].

The adult population of the Nord-Trøndelag County, Norway, has been invited to three main surveys, HUNT1 (1984-86), HUNT2 (1995-97) and HUNT3 (2006-08). Data from this study are extensively used in national and international research, and have per 2012 been the basis of about 600 peer reviewed papers and about 70 doctoral theses. Studies after HUNT1 and 2 indicated only minor potential nonparticipation bias, but these were restricted
Ciomed Central

(c) 2012 Langhammer et al.; licensee BioMed Central Ltd. This is an Open Access article distributed under the terms of the Creative Commons Attribution License (http://creativecommons.org/licenses/by/2.0), which permits unrestricted use, distribution, and reproduction in any medium, provided the original work is properly cited. 
to few topics [2,7]. Due to a substantial decline in participation rate from $88 \%$ in HUNT1, $71 \%$ in HUNT2 to $54 \%$ in HUNT3, an updated thorough nonparticipation study was warranted.

The present study had three main objectives:

a) To study potential participation bias for common symptoms, diseases and socioeconomic status in HUNT3

b) To study mortality by participation status in HUNT

c) To provide dcata as basis for future sensitivity analyses in disease specific studies

\section{Methods}

\section{The HUNT study}

2In each survey of the adult part of the HUNT Study every citizen of Nord-Trøndelag County aged 20 years and older was invited. The population is homogenous, lives in mainly rural areas with five smaller towns, and has a level of education and income a little beneath the national average. However, mortality and health status is fairly representative of Norway [3,8]. The design and methods applied in the three surveys were by and large unchanged, but each time the scientific program was extended [4].

\section{Data sources}

1) The HUNT3 questionnaires. A questionnaire (Q1) was mailed together with the personal invitation, to be completed and delivered when attending the examination stations. At the examination, questionnaire $2(\mathrm{Q} 2)$ and 3 (Q3) were handed out, these should be completed at home and posted to HUNT Research Centre in a prepaid envelope. Q1 and Q2 included questions about quality of life, life style, symptoms, prior or current diseases and health care utilization, while Q3 (9 versions) was aimed at subgroups with specific diseases and use of health care. Some $99.7 \%$ of those delivering Q1 did also participate in the standard examination programme. Nonparticipants received one reminder.

2) Questionnaire for nonparticipants (QNP). About nine months after completion of the HUNT3 survey, a two page questionnaire (QNP) and a prepaid envelope for return were mailed to all nonparticipants in HUNT3 if they were still alive and residing in the county. The questionnaire included identical core questions on symptoms, diseases and life style as in Q1 and Q2, as well as questions on reasons for nonparticipation in HUNT3.

3) General practitioner (GP) data. In 2007 a total of 102 GPs were practising in Nord-Trøndelag County, out of which $2 / 3$ used the electronic patient journal Profdoc, Winmed version 2.2. Among Winmed users, eight practices with 30 GPs were randomly selected for data extraction of selected anonymous data from the patient records during January-May 2011. From patients on the doctors list aged $20-100$ by the $1^{\text {st }}$ of January 2011 these data were extracted: Number of consultations during the last year, diagnoses according to The International Classification of Primary Care codes (ICPC2), prescription of selected drugs in the last year and asthma medication during the last five years according to Anatomical Therapeutic Chemical Classification System (ATC).

4) Register data. Data on dispensed drugs during 2008 for inhabitants of the Nord-Trøndelag County was retrieved from the Norwegian Prescription Database (NorPD) [9]. The invitation file for HUNT 3 including variables for age, sex, and participation status was sent to Statistics Norway [10] for merging with data on mortality, education, income (quintiles), social security and social assistance (sick leave, rehabilitation, time-limited or permanent disability pension), marital status and type of municipality. Data comparisons between participants and nonparticipants were performed in an anonymous file. Education, income and marital status were chosen as status of $1^{\text {st }}$ January 2007, whilst the other variables reflected the study period 2006-2008.

\section{Statistical analyses}

In all study parts the numbers of invited and participating individuals are reported, providing several participation rates as recommended [1]. The participation rates derived from questionnaire data refer to Q1 and QNP. Questions derived from Q2 are marked in the tables. When comparing data from Q1 or Q2, QNP and the extracted GP data, results are stratified by age groups (20-39, 40-59, 60-79 and 80+). In the registry and mortality studies we stratified age into three groups, 20-39, 40-64 and 65+, the latter group mainly being retired. For comparison with extracted GP data, only HUNT3 data derived from the corresponding eight municipalities were used. Data on dispensed drugs from NorPD refers to the entire county for the year 2008 .

The statistical software SPSS version 17 was used for testing differences between proportions with chi square tests, whilst Stata version 11 for Windows was used for estimation of relative risks with binomial regression (generalized linear model with a log link function assuming a negative binomial distribution), for the estimation of hazard ratios of death in Cox proportional regression analyses, and for age adjusted Kaplan Meier plots of survival. In these analyses follow-up time was from August 1986 for HUNT1, August 1997 for HUNT2 and August 2008 for HUNT3 to the date of death or until $4^{\text {th }}$ of July 2010, whichever came first. Start of follow-up was set to two months after the HUNT surveys to avoid the impact of terminally ill subjects during the surveys. 


\section{Variables}

When comparing Q1/Q2 and QNP (Table 1) answers to the question "How is your health at present?" were dichotomized into poor/very poor and good/very good. The mean score of CONOR Mental health Index (MHI) [11], including 7 items each with score 1-4 on mental distress was calculated, and proportions of those scoring above 2.15 are reported. Comparing answers in Q1/Q2 and GP data, combined diagnosis according to ICPC-2 or ATC-codes for medications are reported (Table 2). Anxiety and depressive symptoms were ascertained using the Hospital Anxiety and Depression Score (HADS) [12] in HUNT3, and categorized as dichotomous variables using a cut-off score of $\geq 8$ on the HADSanxiety or HADS-depression, respectively [13].

\section{Ethics}

All participants at HUNT3 were informed and gave written consents to participation in the main and follow-up studies. The Norwegian Data Inspectorate has licensed HUNT Research Centre to store and link data collected in all HUNT surveys. All HUNT surveys, and the present nonparticipant study, are approved by The Regional Committee for Medical and Health Research Ethics.

\section{Results}

In HUNT3, 46567 men and 47293 women aged 20 years or more were invited and 23049 (49.5\%) men and 27758 (58.7\%) women answered at least one question in Q1 (Table 1). The lowest participation rates were found in age groups 20-39 and 80+. The questions were completed by $95-99 \%$ of the participants with minor differences between diseases, symptoms and life style factors. For life style questions (use of alcohol, snuff, smoking and exercise) the proportion of missing increased by age group from about $2 \%$ in the youngest to $12 \%$ among those aged 80 years or more. The first question in Q1 was answered by $97.0 \%$ whilst the last one was answered by $98.6 \%$. The response rate to questions in Q2 varied from $73 \%$ to $80 \%$ out of all who answered Q1.

\section{Comparing HUNT3 questionnaires with nonparticipation questionnaire data}

In all 3241 women and 3677 men returned QNP and had answered at least one question. They represent $6.9 \%$ and $7.9 \%$ of women and men invited to HUNT3 (Table 1). The percentages were similar after exclusion of 498 women and 531 men having died or emigrated between the invitation to HUNT Q1 and QNP. For questions on life style factors missing increased from $1 \%$ to $4 \%$ by increasing age group, for cardiovascular diseases there were $50 \%$ missing data in the youngest age groups. For other diseases and symptoms the proportion of missing increased from $2 \%$ in the youngest group to $10-14 \%$ in the oldest. Among participants at HUNT2 who were invited to HUNT3, some $70.7 \%$ answered Q1 (HUNT3) and 6.4\% QNP compared to $29.3 \%$ and $8.5 \%$ among nonparticipants at HUNT2.

Self-reported body heights and weights were slightly higher and lower, respectively, in QNP compared to measurements of participants at the examination, giving BMI based on measurement 0.6 and $1.1 \mathrm{~kg} / \mathrm{m}^{2}$ higher in men and women. Except for age group 40-59 years, similar proportions in the two groups had visited GP during the last 12 months, but independent of age and sex, larger proportions in the QNP group had been hospitalized compared to the Q1 group.

More participants of QNP compared to Q1 reported poor/very poor health, mental distress and insomnia in the evenings (Table 1). In women 40 years and older chronic disease limiting daily functions was reported more often in the QNP than Q1 group. No difference between groups were found in men at similar age, but in younger men the highest proportion of affirmative answers to this question was found in the Q1 group.

The prevalence of self-reported symptoms varied between the questionnaires by symptom types. A lot of heartburn was more often reported in Q1/Q2 than in QNP in all age groups, and similar patterns were found for symptoms like chronic musculoskeletal pain and urine incontinence in the age group 20-60 years, but with opposite pattern among the oldest (Table 1, Additional file 1 Table S1, Additional file 2 Table S2). For respiratory symptoms (cough, wheezing and breathlessness), headache and migraine there were minor differences without any consistent pattern by sex or age groups.

Compared to Q1, higher proportions in QNP reported chronic diseases such as arterial hypertension (drug treated), myocardial infarction, angina pectoris, stroke, renal disease, diabetes, fibromyalgia, arthrosis and that they ever had sought help for mental problems in age groups 40-59 years and older. Regarding asthma and COPD there were no substantial differences in women, but in men COPD was reported more often in QNP compared to Q1 in all age groups with 55\% difference all over. For hypo- and hyperthyroidism and cancer no between groups difference was found.

Among men above age 39 years, daily smoking and use of snuff were more prevalent in QNP compared to Q1, whilst this was not found among women. In both sexes more never-smokers participated in Q1 compared to QNP. Intake of alcohol 2-3 times a week or more, was reported more often in Q1 than QNP in women, whilst no difference was found among men. In Q1 exercising 2-3 times a week or more, was reported more often than in QNP in both sexes. 
Table 1 Comparisons of anthropometrics (means) and percentages reporting symptoms and diseases between responders to the main questionnaires (Q1 or Q2) and the nonparticipation questionnaire (QNP)

\begin{tabular}{|c|c|c|c|c|c|c|c|c|}
\hline & \multicolumn{4}{|c|}{ Women } & \multicolumn{4}{|c|}{ Men } \\
\hline & Q1 & QNP & $\mathrm{p}$ & $\mathrm{Q} 1+\mathrm{QNP}$ & Q1 & QNP & $\mathrm{p}$ & $\mathrm{Q} 1+\mathrm{QNP}$ \\
\hline Number invited $a$ & 47293 & 19004 & & & 46567 & 23020 & & \\
\hline Number participated & 27758 & 3241 & & 30999 & 23049 & 3677 & & 26726 \\
\hline Percent of invited to HUNT3 & 58.7 & 6.9 & & 65.6 & 49.5 & 7.9 & & 57.4 \\
\hline Height $(\mathrm{cm})^{\#}$ & 164.6 & 166.3 & $<0.01$ & 164.7 & 177.8 & 179.6 & $<0.01$ & 178.0 \\
\hline Weight (kg) ${ }^{\#}$ & 72.9 & 71.5 & $<0.01$ & 72.8 & 86.9 & 86.7 & 0.51 & 86.8 \\
\hline BMI $\left(\mathrm{kg} / \mathrm{m}^{2}\right)^{\#}$ & 26.9 & 25.8 & $<0.01$ & 26.8 & 27.5 & 26.9 & $<0.01$ & 27.4 \\
\hline General practitioner last 12 months & 83.9 & 84.6 & 0.30 & 83.9 & 74.5 & 74.2 & 0.74 & 74.4 \\
\hline Hospitalized last year & 12.4 & 20.1 & $<0.01$ & 13.1 & 10.9 & 14.0 & $<0.01$ & 11.3 \\
\hline Current health poor or very poor & 28.4 & 29.6 & 0.20 & 28.5 & 23.4 & 24.1 & 0.36 & 23.5 \\
\hline Mental distress $£$ & 7.9 & 12.1 & $<0.01$ & 8.3 & 6.3 & 9.4 & $<0.01$ & 6.8 \\
\hline Insomnia many evenings a week & 14.8 & 16.2 & 0.03 & 15.0 & 7.5 & 10.2 & $<0.01$ & 8.0 \\
\hline Wake up early in the morning many days a week & 12.2 & 11.9 & 0.66 & 12.1 & 9.6 & 8.2 & $<0.01$ & 9.4 \\
\hline Chronic disease limiting daily functions & 33.9 & 33.9 & 1.00 & 33.9 & 32.4 & 27.9 & $<0.01$ & 31.8 \\
\hline Daily cough in periods (Q2) & 19.1 & 20.7 & 0.04 & 19.3 & 22.6 & 20.3 & $<0.01$ & 22.2 \\
\hline Attacks of wheezing or breathlessness & 12.4 & 11.3 & 0.09 & 12.3 & 12.3 & 12.2 & 0.95 & 12.3 \\
\hline Allergic rhinitis (Q2) & 23.1 & 25.3 & $<0.01$ & 23.4 & 18.7 & 21.8 & $<0.01$ & 19.2 \\
\hline Heartburn (a lot) (Q2) & 7.1 & 4.4 & $<0.01$ & 6.7 & 7.2 & 4.8 & $<0.01$ & 6.8 \\
\hline Headache (Q2) & 42.1 & 44.7 & $<0.01$ & 42.4 & 27.8 & 27.3 & 0.51 & 27.7 \\
\hline Migraine (Q2) & 10.9 & 11.8 & 0.09 & 11.0 & 5.0 & 5.3 & 0.45 & 5.0 \\
\hline Musculoskeletal pain of more than 3 months & 54.6 & 41.9 & $<0.01$ & 53.0 & 45.1 & 31.6 & $<0.01$ & 42.9 \\
\hline Urine incontinence (Q2) & 26.8 & 20.6 & $<0.01$ & 26.1 & 8.7 & 5.2 & $<0.01$ & 8.2 \\
\hline Medication for arterial hypertension & 20.5 & 24.9 & $<0.01$ & 20.8 & 21.4 & 23.8 & $<0.01$ & 21.7 \\
\hline Myocardial infarction & 1.6 & 3.1 & $<0.01$ & 1.7 & 5.2 & 6.9 & $<0.01$ & 5.4 \\
\hline Angina pectoris & 2.5 & 3.2 & 0.04 & 2.7 & 4.8 & 5.9 & 0.01 & 5.0 \\
\hline Cerebral insult & 2.2 & 3.5 & $<0.01$ & 2.3 & 3.0 & 3.7 & 0.03 & 3.1 \\
\hline Renal disease & 2.6 & 3.9 & $<0.01$ & 2.7 & 2.5 & 3.8 & $<0.01$ & 2.7 \\
\hline Asthma & 10.4 & 10.9 & 0.39 & 10.4 & 9.4 & 10.5 & 0.04 & 9.5 \\
\hline COPD or chronic bronchitis & 3.3 & 3.9 & 0.14 & 3.3 & 3.4 & 5.3 & $<0.01$ & 3.7 \\
\hline Diabetes & 3.8 & 5.7 & $<0.01$ & 4.0 & 4.9 & 6.6 & $<0.01$ & 5.2 \\
\hline Cancer & 5.6 & 5.6 & 0.94 & 5.6 & 4.9 & 4.6 & 0.55 & 4.8 \\
\hline Osteoporosis & 5.3 & 5.9 & 0.20 & 5.3 & 0.7 & 1.1 & 0.03 & 0.8 \\
\hline Fibromyalgia & 6.3 & 7.4 & 0.03 & 6.4 & 0.8 & 1.3 & $<0.01$ & 0.9 \\
\hline Arthrosis & 18.8 & 21.4 & $<0.01$ & 19.0 & 10.3 & 11.9 & 0.01 & 10.5 \\
\hline Sought help for mental problem & 16.9 & 20.6 & $<0.01$ & 17.7 & 9.9 & 11.7 & $<0.01$ & 10.1 \\
\hline Hyperthyreosis & 2.8 & 3.0 & 0.56 & 2.8 & 0.9 & 0.5 & 0.05 & 0.8 \\
\hline Hypothyreosis & 9.3 & 10.0 & 0.30 & 9.4 & 2.3 & 1.8 & 0.06 & 2.2 \\
\hline Never-smoker $\S$ & 47.3 & 44.4 & $<0.01$ & 47.0 & 44.3 & 41.1 & $<0.01$ & 43.8 \\
\hline Ex-smoker & 27.4 & 26.1 & 0.13 & 27.3 & 35.2 & 31.1 & $<0.01$ & 34.6 \\
\hline Occasional smoker & 9.4 & 9.3 & 0.92 & 9.4 & 9.7 & 9.2 & 0.38 & 9.6 \\
\hline Daily smoker & 20.6 & 20.2 & 0.59 & 20.6 & 16.9 & 18.7 & $<0.01$ & 17.1 \\
\hline Daily use of snuff & 1.2 & 1.9 & $<0.01$ & 1.3 & 13.8 & 17.0 & $<0.01$ & 14.3 \\
\hline
\end{tabular}


Table 1 Comparisons of anthropometrics (means) and percentages reporting symptoms and diseases between responders to the main questionnaires (Q1 or Q2) and the nonparticipation questionnaire (QNP) (Continued)

\begin{tabular}{lrrrrrrrr}
\hline Alcohol $\geq 2-3$ times a week & 12.0 & 9.5 & $<0.01$ & 11.3 & 18.8 & 17.8 & 0.16 & 18.6 \\
Exercise $\geq 2-3$ times a week & 20.5 & 14.0 & $<0.01$ & 19.8 & 17.3 & 13.9 & $<0.01$ & 16.9 \\
\hline
\end{tabular}

Questions from Q2 are marked.

a Invited to QNP, persons having died or emigrated between HUNT3 and QNP are excluded

\# Height and weight measured at the screening stations, self-reported in QNP.

$\S$ Questions on tobacco smoking; included in $\mathrm{n}$ if answered at least one of the smoking related questions.

$£$ CONOR Mental Health Index (CONOR MHI) consists of 7 questions on mental distress with score 1-4. Mean score calculated and cut-off for dichotomization was $\geq 2.15$.

Corresponding data stratified by age and sex are given in Table S1 and Table S2.

When combining data from Q1 and QNP the response rate increased to $65.6 \%$ and $57.4 \%$ out of those invited to HUNT3 for women and men, respectively. For most symptoms and diseases, the prevalence estimates did not change substantially by combining these data sources (Table 1).

\section{Comparing HUNT3 questionnaire with general practice data}

In all, data on 13821 women and 14454 men were extracted from GP records. The age and sex distribution of the GP population was representative of the county population (Table 2).

A lot of heartburn was reported less often in HUNT than diagnosed heartburn or esophagitis by GPs (Table 3), and higher prevalence was found for prescriptions of medications mainly used at these indications (data not shown). The proportion of patients with diagnoses of cardiovascular diseases (angina, myocardial infarction and stroke) in GP records was higher than the prevalence of corresponding self-reported diseases. There was, however, close agreement between the two data sets regarding use of antihypertensive treatment. Interestingly, data from NorPD showed more prevalent use of such drugs, but these are also indicated for other diseases than arterial hypertension. In HUNT3 there were questions on each of the diagnoses of spondylarthritis and rheumatoid arthritis, whilst these diseases have a common diagnostic code in ICPC-2. Combining these diagnoses showed a fair agreement between the two sources, and similar consistency was also found for arthrosis and osteoporosis in women, but GP-data indicated $20 \%$ higher prevalence of arthrosis among men than reported by HUNT participants.

A high proportion of participants in HUNT3 reported bothersome headache, but the prevalence of the diagnosis of headache in GP records was close to one third of this. However, for the more specific diagnosis of migraine, the prevalence in general practice was only slightly lower than self-reported prevalence in HUNT3. The frequency of migraine attacks varies from a few attacks per decade to many attacks a week; in line with this NorPD data showed that only $0.8 \%$ of men and $3.4 \%$ of women had migraine medication dispensed during one year (2008).

Data in HUNT3 were not eligible for direct comparison of prevalence of anxiety and depression with the GP data. However, the prevalence of diagnosed anxiety by

Table 2 Number of persons, mean age and percentages having consulted general practitioner in the last 12 months among those having answered HUNT3 questionnaire Q1 and those being registered at the general practices

\begin{tabular}{|c|c|c|c|c|c|c|c|c|}
\hline \multirow[t]{2}{*}{ Characteristics } & \multicolumn{4}{|c|}{ Women age groups } & \multicolumn{4}{|c|}{ Men age groups } \\
\hline & $20-39$ & $40-59$ & $60-79$ & $80+$ & $20-39$ & $40-59$ & $60-79$ & $80+$ \\
\hline \multicolumn{9}{|l|}{ Numbers } \\
\hline HUNT3: Invited & 8606 & 10577 & 6274 & 1400 & 8528 & 10093 & 6537 & 2299 \\
\hline HUNT3: Answered Q1 & 2785 & 5657 & 4057 & 552 & 3898 & 6510 & 4631 & 782 \\
\hline GPs: Listed patients aged $\geq 20$ years & 4364 & 5346 & 3926 & 818 & 3848 & 5209 & 3559 & 1205 \\
\hline \multicolumn{9}{|l|}{ Mean age } \\
\hline HUNT3: Mean age within age groups among all invited & 29.7 & 49.4 & 67.7 & 84.4 & 29.7 & 49.4 & 68.1 & 85.3 \\
\hline HUNT3: Mean age within age groups among all Q1 part. & 31.4 & 50.5 & 68.0 & 83.8 & 31.2 & 50.3 & 68.2 & 84.2 \\
\hline GPs: Mean age within age groups in the patient population & 29.0 & 49.4 & 67.6 & 84.8 & 29.4 & 49.2 & 68.0 & 85.7 \\
\hline \multicolumn{9}{|l|}{ Consultations } \\
\hline HUNT3 Reported GP visit last year & 65.0 & 71.7 & 86.3 & 93.7 & 82.7 & 82.3 & 89.7 & 92.3 \\
\hline GP: Registered $\geq 1$ visit to GP last year & 58.9 & 71.3 & 86.5 & 92.7 & 78.9 & 84.5 & 90.2 & 89.2 \\
\hline
\end{tabular}

Data restricted to the municipalities including eight randomly selected general practices (GPs). The 28872 HUNT3 participants represented 57\% of invited in these municipalities. 
Table 3 Prevalence data (\%) based on HUNT3 questionnaires (Q1 or Q2) and general practitioner diagnoses (GPD)

\begin{tabular}{|c|c|c|c|c|c|c|c|c|}
\hline & \multicolumn{4}{|c|}{ Women age groups } & \multicolumn{4}{|c|}{ Men age groups } \\
\hline & $20-39$ & $40-59$ & $60-79$ & $80+$ & $20-39$ & $40-59$ & $60-79$ & $80+$ \\
\hline \multicolumn{9}{|l|}{ Heart burn } \\
\hline Q2: A lot of heart burn & 6.1 & 7.9 & 6.3 & 6.2 & 4.9 & 6.3 & 8.6 & 7.9 \\
\hline GPD: Heart burn or reflux (D03/D84) & 3.9 & 8.2 & 10.0 & 11.0 & 2.5 & 7.6 & 12.1 & 12.0 \\
\hline \multicolumn{9}{|l|}{ Cardiovascular diseases } \\
\hline Q1: Angina pectoris & 0.3 & 1.5 & 9.6 & 21.4 & 0.2 & 0.7 & 4.4 & 15.5 \\
\hline GPD: Angina pectoris (K74) & 0.1 & 2.2 & 13.9 & 26.4 & 0 & 0.8 & 6.8 & 21.1 \\
\hline Q1: Myocardial infarction & 0.1 & 2.3 & 10.1 & 21.2 & 0.0 & 0.5 & 3.0 & 8.6 \\
\hline GPD: Myocardial infarction (K75or K76) & 1.0 & 3.3 & 12.9 & 18.8 & 0.5 & 1.3 & 4.7 & 10.4 \\
\hline Q1: Cerebral insult & 0.6 & 1.5 & 5.4 & 11.6 & 0.3 & 1.1 & 3.9 & 8.6 \\
\hline GPD: Cerebral insult (K90 + 91) & 0.4 & 2.2 & 7.3 & 17.0 & 0.4 & 1.4 & 5.7 & 14.2 \\
\hline Q1: Arterial hypertension & 1.2 & 14.7 & 38.1 & 44.1 & 2.1 & 12.7 & 36.9 & 49.8 \\
\hline GPD: Arterial hypertension (K86 or K87) & 2.7 & 14.7 & 37.4 & 42.2 & 2.2 & 12.9 & 37.1 & 49.4 \\
\hline NorPD: Drugs arterial hyper-tension (C02-03, 07-09) & 1.7 & 16.0 & 51.5 & 70.3 & 2.2 & 15.7 & 49.5 & 67.7 \\
\hline
\end{tabular}

Inflammatory and musculoskeletal diseases

Q1: Spondylarthritis or

rheumatoid arthritis

GPD: Spondylarthritis or rheumatoid arthritis (L88)

Q1: Arthrosis

GPD: Arthrosis hip or knee $(\mathrm{L} 89+90+91)$

Q1: Osteoporosis

GPD: Osteoporosis L95

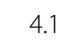

0.8

1.7

0.1

0.2

Neurological diseases

Q1: Headache

GPD: Headache (N01)

Q1: Migraine

GPD: Migraine (N89)

NorPD: Use of migraine drugs (N02)

Q1: Epilepsy

GPD: Epilepsy (N88)

\section{Mental diseases and insomnia}

Q2: HADS anxiety score $\geq 8 \#$

GPD: Anxiety or feeling of anxiety (P $01+74+79)$

Q2: HADS depression score $\geq 8 \#$

GPD: Depression or feeling of depression (P $03+76)$

Q2: Insomnia many evenings or mornings a week

GPD: Sleeping disorder (P06)

\section{Respiratory diseases}

Q1: COPD or chronic bronch

GPD: COPD or chronic bronchitis (R95)

Q1: Asthma

GPD: Asthma (R96)

Q1: Use of asthma or copd drugs in the last 5 years

GP prescription asthma drugs in the last 5 year (R03)
10.8

3.1

3.8

1.0

1.5

11.9

6.7

6.4

11.0

11.6

6.3

1.0

0.1

10.5

10.6

8.1

7.4
1.5

$$
\begin{aligned}
& 4.1 \\
& 3.4 \\
& 6.1 \\
& 7.5 \\
& 0.3 \\
& 0.6
\end{aligned}
$$

34.3

9.8

9.9
3.5

4.4

$1.0 \quad 1.0$

1.5

1.7

$1.9 \quad 11.7$

9.4

18.1

8.6

2.0

1.9

9.3

$\begin{array}{ll}0.6 & 7.0\end{array}$

17.5

8.7

$\begin{array}{rr}5.3 & 6.0 \\ 4.5 & 5.6 \\ 17.2 & 23.3 \\ 21.5 & 29.8 \\ 1.2 & 3.1 \\ 1.5 & 2.9\end{array}$

\section{9}

1.5

1.0

1.7

0.3

0.2

18.7

10.7

56.9

$$
6.1
$$

18.6

10.4

2.7

2.6

0.5

$$
3.4
$$

$$
9.7
$$

$$
6.2
$$$$
11.1
$$$$
16.2
$$$$
15.4
$$$$
19.6
$$$$
13.1
$$

18.8

$$
24.0
$$

$$
6.3
$$

\section{7}

$\begin{array}{rr}7.2 & 8.8 \\ 7.9 & 8.7 \\ 34.2 & 45.5 \\ 33.6 & 43.4 \\ 11.1 & 20.6 \\ 10.8 & 22.7\end{array}$

$$
1.4
$$

$$
47.7
$$$$
16.5
$$$$
26.8
$$$$
\begin{aligned}
& 26.8 \\
& 12.6
\end{aligned}
$$$$
16.6
$$$$
11.2
$$$$
11.6
$$$$
4.9
$$$$
5 .
$$$$
7.1
$$$$
2.0
$$$$
1.4
$$$$
1.4
$$$$
0.7
$$$$
1.5
$$

$5.6 \quad 5.4$

$\begin{array}{rr}5.6 & 5.4 \\ 7.9 & 13.2\end{array}$

1.5
0.2
12.4

\section{4}

9.4

7.2

12.4

$\begin{array}{lll}9.2 & 10.0 & 10.4\end{array}$

11.3

9.6

10.4

15.1

17.4

9.8

$\begin{array}{rr}15.6 & 13.2 \\ 14.0 & 15.4 \\ 9.8 & 16.3 \\ 28.0 & 21.7 \\ 25.8 & 25.3 \\ 21.7 & 32.4\end{array}$

$\begin{array}{rrr}2.7 & 4.6 & 4.2 \\ 1.8 & 7.2 & 7.0 \\ 9.4 & 10.4 & 8.6 \\ 9.7 & 11.9 & 9.9 \\ 9.6 & 12.5 & 9.7 \\ 11.4 & 17.3 & 12.6\end{array}$


Table 3 Prevalence data (\%) based on HUNT3 questionnaires (Q1 or Q2) and general practitioner diagnoses (GPD) (Continued)

\begin{tabular}{|c|c|c|c|c|c|c|c|c|}
\hline NorPD: Use of asthma drugs in 2008 (R03) & 4.6 & 5.6 & 11.6 & 14.2 & 5.7 & 7.7 & 13.0 & 9.1 \\
\hline \multicolumn{9}{|l|}{ Skin diseases } \\
\hline Q1: Psoriasis & 4.1 & 6.8 & 7.0 & 3.8 & 3.3 & 6.2 & 6.6 & 4.1 \\
\hline GPD: Psoriasis (S91) & 2.0 & 4.6 & 5.5 & 4.6 & 2.7 & 4.5 & 5.8 & 2.8 \\
\hline \multicolumn{9}{|l|}{ Endocrine disorders } \\
\hline Q1: Hyperthyreosis & 0.3 & 0.7 & 1.3 & 2.5 & 1.4 & 2.6 & 3.4 & 3.2 \\
\hline GPD: Hyperthyreosis (T85) & 0.2 & 0.5 & 0.7 & 0.7 & 0.6 & 1.9 & 2.0 & 2.0 \\
\hline Q1: Hypothyreosis & 0.6 & 2.1 & 2.9 & 5.3 & 4.1 & 8.0 & 12.3 & 12.1 \\
\hline GPD: Hypothyreosis (T86) & 1.4 & 1.9 & 4.2 & 6.7 & 3.2 & 7.8 & 12.7 & 13.8 \\
\hline GP prescription thyroid hormone (H03AA01) & 0.5 & 1.5 & 3.3 & 5.1 & 2.2 & 7.0 & 12.1 & 12.5 \\
\hline NorPD: Use of thyroid hormone (H03AA01) & 0.5 & 2.0 & 3.7 & 5.9 & 2.6 & 7.9 & 14.2 & 13.4 \\
\hline Q1: Diabetes mellitus & 0.8 & 3.4 & 9.2 & 9.2 & 0.8 & 2.4 & 6.9 & 9.7 \\
\hline GPD: Diabetes mellitus (T89+90) & 1.2 & 4.8 & 13.7 & 16.3 & 1.4 & 3.6 & 10.4 & 13.0 \\
\hline GP prescription antidiabetic drug (A10A or A10B) & 0.8 & 4.0 & 10.9 & 10.9 & 1.2 & 2.8 & 7.9 & 8.8 \\
\hline NorPD: Antidiabetic drug (A10A or A10B) & 1.1 & 4.1 & 11.1 & 11.7 & 1.5 & 2.6 & 8.4 & 9.2 \\
\hline \multicolumn{9}{|l|}{ Urinary tract } \\
\hline Q2: Urinary incontinence & 4.7 & 7.6 & 10.4 & 13.1 & 22.2 & 27.5 & 27.4 & 32.8 \\
\hline GPD: Urinary incontinence (U04) & 1.0 & 0.5 & 3.0 & 8.7 & 2.2 & 6.8 & 10.5 & 22.0 \\
\hline
\end{tabular}

HUNT data are restricted to the municipalities being represented by eight randomly selected general practices, and include 28872 HUNT3 participants ( $57 \%$ of invited in these municipalities). Data from Norwegian Prescription Registry (NorPD) include the entire county for the year 2008.

\# Hospital Anxiety and Depression Scale (HADS) 14 items, cut-off 8 indicate minor, moderate and severe disease (REF).

In parenthesis: For diagnosis - codes according to the International Classification of Primary Care (ICPC2), for medication codes according to The Anatomical

Therapeutic Chemical Classification System (ATC).

GP was slightly lower compared to the prevalence having a HADS-anxiety symptom score of 8 or higher. Corresponding comparison between diagnosed depression and HADS depression symptom score 8 or higher showed much lower estimated prevalence of depression amongst HUNT3 participants. Among the oldest age groups sleeping disorders were more often diagnosed in GP records than reported by HUNT participants, whilst the opposite pattern was found in younger age groups.

Higher prevalence of COPD diagnosis was found in GP data compared to self-reported data in HUNT3 among those aged 60 years and older, whilst there were relatively small differences regarding asthma. Reported use of asthma or COPD medication in HUNT3 was somewhat lower compared to data from GP, especially in the older age groups.

For hypothyreosis and corresponding prescribed and dispensed thyroid hormones there were rather consistent data, whilst hyperthyreosis was less often diagnosed in GP records. The diagnosis of diabetes was more prevalent in the GP population than the self-reported data from HUNT3 indicated. Data on both prescribed and dispensed insulin and oral medication for diabetes suggested an underestimation of prevalence data from HUNT3, as a substantial number with diabetes also are treated with life style only. Selfreported urine incontinence was more prevalent in HUNT3 compared to the proportion having been diagnosed by GPs.

\section{Comparing data from GP records, questionnaire Q1 and questionnaire QNP}

Comparing over all prevalence either of diagnoses registered in general practices and self-reported data from Q1 and Q2 show minor differences for asthma (Figure 1). For persons 60 years and older, there were similar patterns for apoplexia, myocardial infarction, COPD and diabetes, with lowest prevalence in Q1, intermediate in GP-data and highest among QNP-participants. Assuming that the prevalences of chronic diseases found in the QNP group were representative for the entire nonparticipation group 60 years and older, the combined prevalences for nonparticipants and Q1 participants compared to estimates from GP records, would be 6.6 versus $8.4 \%$ for apoplexia, 9.8 versus $10.0 \%$ for myocardial infarction, 9.9 versus $10.3 \%$ for asthma, 5.7 versus $8.0 \%$ for COPD and 10.3 versus $12.6 \%$ for diabetes.

Among persons younger than 60 years, symptomatic diseases like COPD, migraine and insomnia were more prevalent in Q1 and QNP data than diagnosed in general practice.

\section{Self-reported reasons for nonparticipation}

About 10\% reported that they had not received invitation to HUNT3 (Table 4). Otherwise the most important reason for nonparticipation was lack of time or inconvenient 


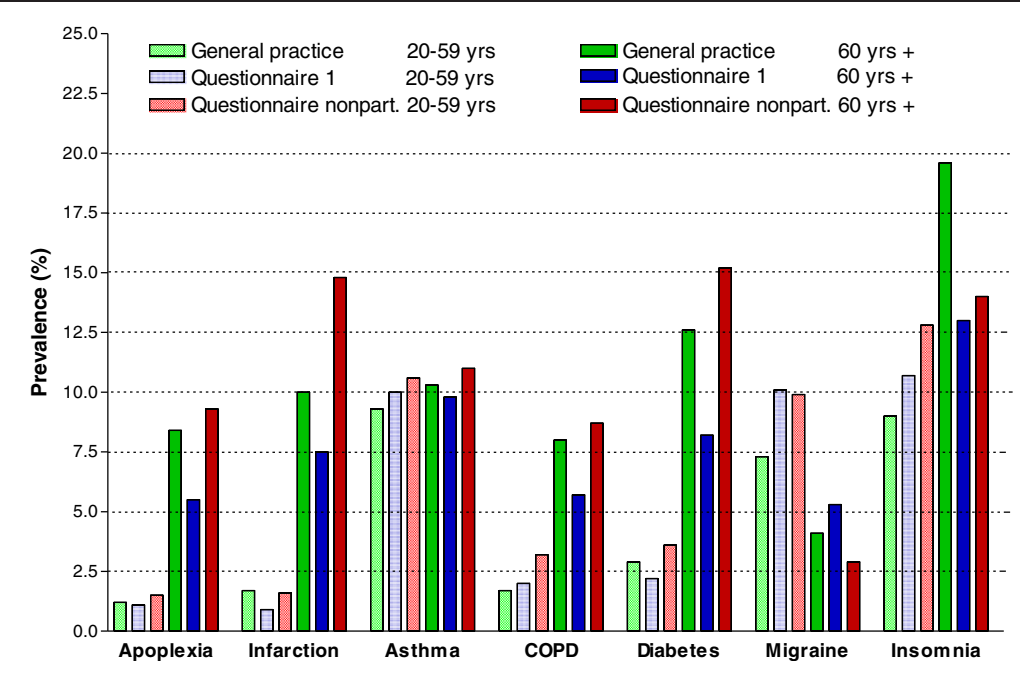

Figure 1 Prevalence of diseases (\%) based on GP records, HUNT questionnaire 1 (Q1) and QNP by age group.

session, this was reported by $50.7 \%$ in women and $56.6 \%$ in men. Among the two oldest age groups, $4.0 \%$ of women and $6.4 \%$ of men reported they would have no benefit of such examinations, while $11.7 \%$ of women and $7.7 \%$ of men reported being too ill to participate.

\section{Comparing participants and non-participants in national register data}

The anonymous file included data on a) participants (27 758 women and 23049 men), b) those having answered QNP (3241 women and 3677 men) and c) those with no participation (16 294 women and 19841 men). The analyses include group "a" and "c". Participation in HUNT depended on sex, age, marital status, education and income (Table 5). In those who received disability pension the participation was lower, and even lower in those receiving social benefit compared to those not receiving social security money. The participation was lower in urban compared to rural municipalities.
Nonparticipants of HUNT surveys displayed a higher mortality even many years after the surveys took place, with increased mortality of 50\%, $72 \%$ and $180 \%$ for nonparticipants compared to participants in HUNT1, HUNT2 and HUNT3, respectively (Table 6). Figure 2, 3 and 4 show corresponding survival curves of participants and nonparticipants of HUNT1 to 3 using age as the timeline and Figure 5, 6 and 7 show the proportion having died, adjusted for age (at 50 years), by time since the HUNT surveys. Interestingly, there are similar patterns for risk of death between participants and nonparticipants in surveys with participation rate varying from 88 to $54 \%$.

\section{Discussion}

Participation rates in HUNT3 depended on age, sex, socioeconomic status and type of symptoms and diseases. Among nonparticipants, the prevalence of common chronic diseases was higher compared to that reported by participants. This included cardiovascular diseases and diabetes mellitus, a pattern confirmed by

Table 4 Percentages reporting reasons for nonparticipation in the HUNT study among 3241 women (W) and 3677 men (M) having answered the nonparticipation questionnaire (QNP)

\begin{tabular}{|c|c|c|c|c|c|c|c|c|c|c|c|}
\hline \multirow[t]{2}{*}{ Reasons } & \multicolumn{2}{|c|}{ 20-39 years } & \multicolumn{2}{|c|}{ 40-59 years } & \multicolumn{2}{|c|}{$60-79$ years } & \multicolumn{2}{|c|}{$80+$ years } & \multicolumn{3}{|c|}{ All age groups } \\
\hline & W & M & W & $M$ & W & $M$ & W & $M$ & W & $M$ & $\mathbf{p}^{\S}$ \\
\hline Did not receive the invitation & 13.3 & 14.9 & 6.2 & 9.3 & 8.5 & 9.1 & 8.0 & 10.7 & 9.5 & 11.1 & 0.02 \\
\hline Had not time /inconvenient session & 60.7 & 64.5 & 54.9 & 61.9 & 34.8 & 40.2 & 14.3 & 20.8 & 50.7 & 56.6 & $<0.01$ \\
\hline Don't rely on such examinations & 0.2 & 0.9 & 1.1 & 1.6 & 1.7 & 2.2 & 0.4 & 2.0 & 0.8 & 1.5 & $<0.01$ \\
\hline No benefit of such examinations & 0.3 & 1.7 & 1.6 & 1.8 & 3.1 & 4.8 & 6.3 & 8.1 & 1.7 & 2.6 & $<0.01$ \\
\hline Too ill to attend the study & 1.4 & 0.6 & 3.3 & 1.2 & 7.2 & 5.5 & 23.7 & 19.5 & 4.7 & 2.6 & $<0.01$ \\
\hline Questions I did not wish to answer & 2.1 & 1.2 & 3.9 & 3.5 & 6.8 & 7.0 & 3.6 & 4.0 & 3.7 & 3.5 & 0.61 \\
\hline Other reason & 25.1 & 17.5 & 30.0 & 22.1 & 32.1 & 27.2 & 24.6 & 18.8 & 28.1 & 21.5 & $<0.01$ \\
\hline
\end{tabular}

$\S$ p-values for chi-square tests comparing all men and women. 
Table 5 Prevalence ratio and absolute difference (\%) of participation $(n=50807)$ versus no participation* $(n=36$ 135) in the HUNT3 main questionnaire by different characteristics

\begin{tabular}{|c|c|c|c|c|c|c|}
\hline \multirow[t]{2}{*}{ Characteristic } & \multicolumn{3}{|c|}{ Prevalence ratio } & \multicolumn{3}{|c|}{ Difference in participation (\%) } \\
\hline & Crude & Adjusted & $95 \% \mathrm{Cl}$ & Crude & Adjusted & $95 \% \mathrm{Cl}(\%)$ \\
\hline Sex (women/men) & 1.17 & 1.23 & $1.20,1.26$ & 9.2 & 12.6 & $11.8,13.3$ \\
\hline \multicolumn{7}{|l|}{ Age group } \\
\hline 20-39 year & 1 & 1 & Reference & 0 & 0 & Reference \\
\hline 40-59 year & 1.63 & 1.45 & $1.40,1.50$ & 25.2 & 19.1 & $18.2,20.0$ \\
\hline 60-79 year & 1.88 & 1.74 & $1.68,1.81$ & 34.7 & 29.9 & $29.0,30.8$ \\
\hline $80+y r s$ & 1.12 & 1.23 & $1.16,1.30$ & 4.8 & 10.7 & $9.2,12.1$ \\
\hline \multicolumn{7}{|l|}{ Education } \\
\hline 9 year or less & 1 & 1 & Reference & 0 & 0 & Reference \\
\hline 10-12 year & 1.28 & 1.27 & $1.23,1.30$ & 13.6 & 13.6 & $12.8,14.5$ \\
\hline University & 1.39 & 1.36 & $1.31,1.41$ & 19.0 & 17.4 & $16.4,18.4$ \\
\hline \multicolumn{7}{|l|}{ Marital status } \\
\hline Unmarried & 1 & 1 & Reference & 0 & 0 & Reference \\
\hline Divorced/Widower & 1.27 & 1.01 & $0.97,1.05$ & 11.6 & -1.8 & $-3.0,-0.6$ \\
\hline Married/cohabits & 1.64 & 1.29 & $1.25,1.33$ & 27.3 & 14.5 & $13.5,15.4$ \\
\hline \multicolumn{7}{|l|}{ Income } \\
\hline Quintile 1 & 1 & 1 & Reference & 0 & 0 & Reference \\
\hline Quintile 3 & 1.39 & 1.32 & $1.09,1.60$ & 15.9 & 15.1 & $10.0,20.1$ \\
\hline Quintile 5 & 1.49 & 1.42 & $1.17,1.73$ & 20.4 & 20.4 & $15.6,25.1$ \\
\hline \multicolumn{7}{|l|}{ Municipality } \\
\hline Urban / rural & 0.93 & 0.91 & $0.89,0.93$ & 6.1 & -5.6 & $-6.4,-4.7$ \\
\hline \multicolumn{7}{|l|}{ Social security \# } \\
\hline Disability pension & 0.97 & 0.92 & $0.88,0.96$ & -19.2 & -6.5 & $-7.8,-5.2$ \\
\hline Social benefit & 0.43 & 0.61 & $0.56,0.67$ & -32.8 & -17.9 & $-20.2,-15.5$ \\
\hline
\end{tabular}

*Participants that answered the nonparticipation questionnaire (QNP) were not included.

a Binomial regression, adjusted for all other variables except social security factors.

\#Analysis restricted to subjects below 65 years of age and all variables entered in the adjusted model.

prevalence data based on diagnosis by GPs. Contrary to this, at least among people younger than 80 years, common problems like musculoskeletal pain, urine incontinence and headache were reported more often in participants compared to nonparticipants. The study confirms associations between participation and marital and socioeconomic status, and maintenance of increased risk of death for nonparticipants even many years after the surveys. Combining data from different sources provides the opportunity for future sensitivity analyses of prevalence, incidence and association studies.

Except for the Tromsø Study [14], most national $[3,5,6,15]$ and international studies $[1,16,17]$ have reported corresponding reduction in participation rate as the HUNT study. Reasons for the increase of nonparticipation in population based studies are thoroughly discussed by Galea et al. [1], and may also be relevant to the Norwegian population; People might be overloaded with invitations to research and marketing surveys, there is a general decrease in volunteerism parallel to decrease in participation in organizations and social activities, there might be lack of immediate benefit for the individual participant and, generally, there is an increasing disillusionment with science due to conflicting results between different studies and changing recommendations for behavioral risk factors. Further, more complex procedures regarding informed consent and study protocol as well as the burden of being invited to follow-up studies, might decrease study participation $[18,19]$.

The HUNT surveys have also become more complex and demanding for participants with more comprehensive questionnaires, interviews and examinations. Further, in order to keep to laws and regulations for medical research, an eight pages information folder was sent together with the personal invitation and consent form, even though invited persons prefer more simple forms [18]. Increased number and size of follow-up questionnaires (Q2 and Q3s), however, have not influenced a stable response rate of these of about $75-80 \%$ among those having attended the examination stations 
Table 6 Overall and sex specific age adjusted mortality (hazard ratio with $95 \% \mathrm{Cl}$ ) according to participation in the HUNT 1, HUNT 2 and the HUNT 3 study

\begin{tabular}{|c|c|c|c|c|}
\hline Participation & $\mathrm{N}$ & Deaths & Hazard ratio & $95 \% \mathrm{Cl}$ \\
\hline \multicolumn{5}{|c|}{ HUNT 1 (1984-86) } \\
\hline \multicolumn{5}{|l|}{ Women } \\
\hline Participated & 38698 & 13450 & 1.00 & Reference \\
\hline Not participated & 3571 & 1300 & 1.51 & $1.43-1.60$ \\
\hline \multicolumn{5}{|l|}{ Men } \\
\hline Participated & 36928 & 14206 & 1.00 & Reference \\
\hline Not participated & 5018 & 1391 & 1.55 & $1.46-1.64$ \\
\hline \multicolumn{5}{|l|}{ Overall } \\
\hline Participated & 75626 & 27656 & 1.00 & Reference \\
\hline Not participated & 8589 & 2691 & 1.50 & $1.44-1.57$ \\
\hline \multicolumn{5}{|c|}{ HUNT 2 (1995-97) } \\
\hline \multicolumn{5}{|l|}{ Women } \\
\hline Participated & 34469 & 5087 & 1.00 & Reference \\
\hline Not participated & 9700 & 2833 & 1.82 & $1.74-1.91$ \\
\hline \multicolumn{5}{|l|}{ Men } \\
\hline Participated & 30237 & 5497 & 1.00 & Reference \\
\hline Not participated & 12625 & 2261 & 1.64 & $1.56-1.73$ \\
\hline \multicolumn{5}{|l|}{ Overall } \\
\hline Participated & 64706 & 10584 & 1.00 & Reference \\
\hline Not participated & 22325 & 5094 & 1.72 & $1.66-1.78$ \\
\hline \multicolumn{5}{|c|}{ HUNT 3 (2006-08) } \\
\hline \multicolumn{5}{|l|}{ Women } \\
\hline Participated & 27652 & 835 & 1.00 & Reference \\
\hline Not participated & 19405 & 225 & 3.33 & $2.86-3.87$ \\
\hline \multicolumn{5}{|l|}{ Men } \\
\hline Participated & 22918 & 367 & 1.00 & Reference \\
\hline Not participated & 23443 & 702 & 2.41 & $2.12-1.75$ \\
\hline \multicolumn{5}{|l|}{ Overall } \\
\hline Participated & 50571 & 619 & 1.00 & Reference \\
\hline Not participated & 42848 & 1555 & 2.80 & 2.54-3.09 \\
\hline
\end{tabular}

Adjusted for age by using age as the time scale.

The following subjects are excluded from the analyses: Persons $<20$ years of age at baseline study, and deaths between invitation and August 1986, August 1997, and August 2008 for HUNT1, HUNT2 and HUNT3, respectively. The number of participants and nonparticipants therefore are lower than previously for the entire study population.

in three surveys. This indicates that the length and number of questionnaires have minor effect on the all over participation in those who from the start had decided to participate [20-22]. Our data show higher participation rate in HUNT3 among persons previously having participated in HUNT2 compared to nonparticipants, this is in line with results from another Norwegian Cohort Study [23]. Previous participation status in HUNT2 did, however, not influence the participation rate for QNP,

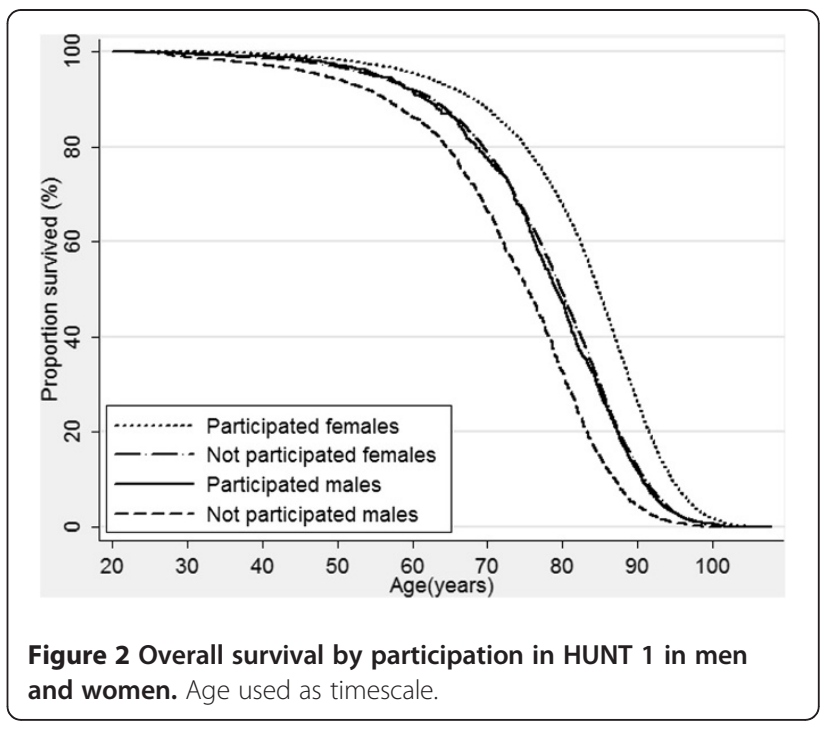

indicating similar attitude to contribute in data collection by short questionnaires in participants and nonparticipants.

Low participation rates among persons under the age of 40 probably reflects less opportunity to spend time, limited short time benefit for a rather healthy age group $[1,24]$ and less altruistic attitude in contributing to research [1]. Higher prevalence of chronic diseases having regular follow-up by health care among nonparticipants and opposite pattern for bothersome, but more trivial symptoms in HUNT3, do support potential benefit for the individual person to be of importance when considering participation. With increasing diagnostic and therapeutic opportunities in the health care during the last decades, present surveys are considered less as a supplement to the health care.

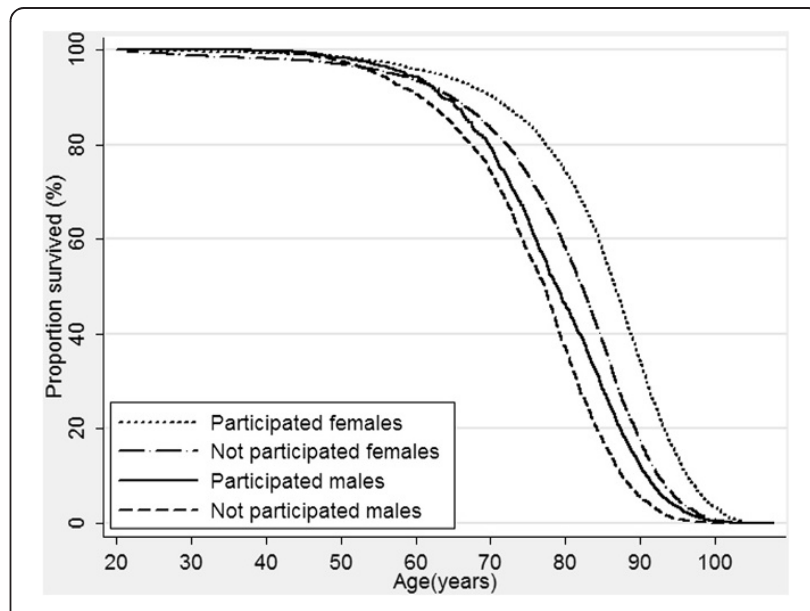

Figure 3 Overall survival by participation in HUINT 2 in men and women. Age used as timescale. 


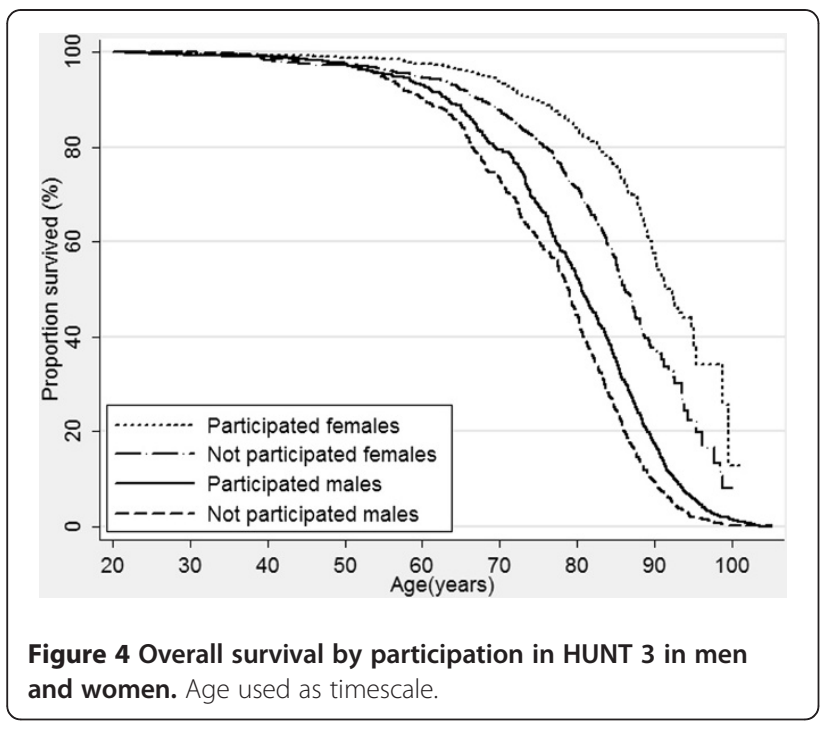

The present study confirms previous studies having reported low participation among people who are young, unmarried, and belonging to lower socioeconomic groups [5,6,21,25-28]. Interestingly, also in the HUNT Study persons in higher socioeconomic groups, with presumably highest time pressure, participated more often compared with lower socioeconomic groups, indicating that motivation and attitude to research are important.

About $10 \%$ of nonparticipants claimed that they had not received the invitation. We have no indication that this can be explained by failure in the post delivery. However, the invitations were sent in plastic foils, and this could have been taken as advertising leaflets and therefore not read. Economic costs should not have much influence on the participation rate; the participation was free of charge and most people were

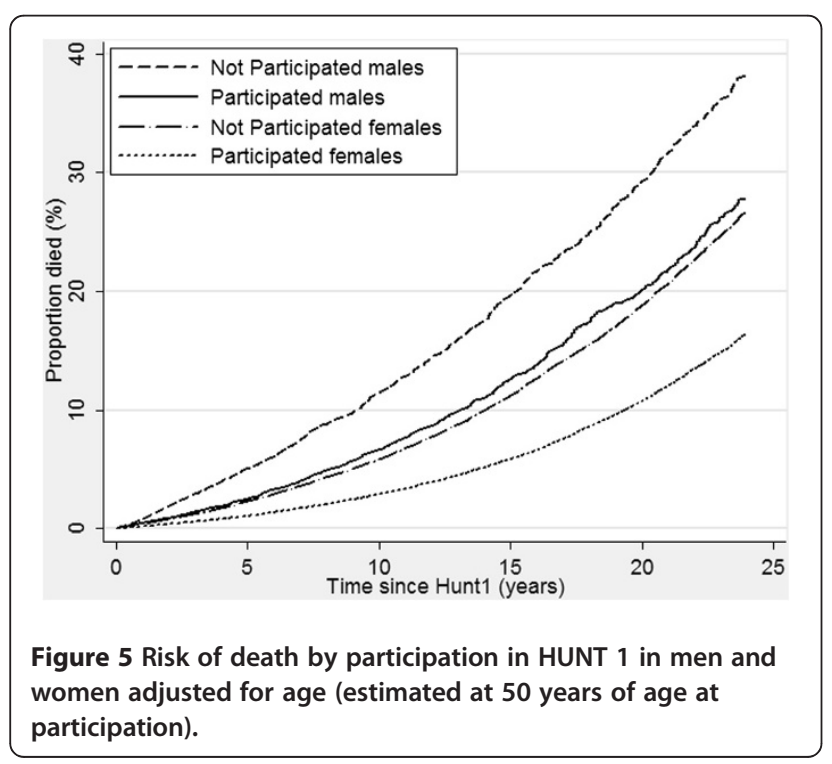

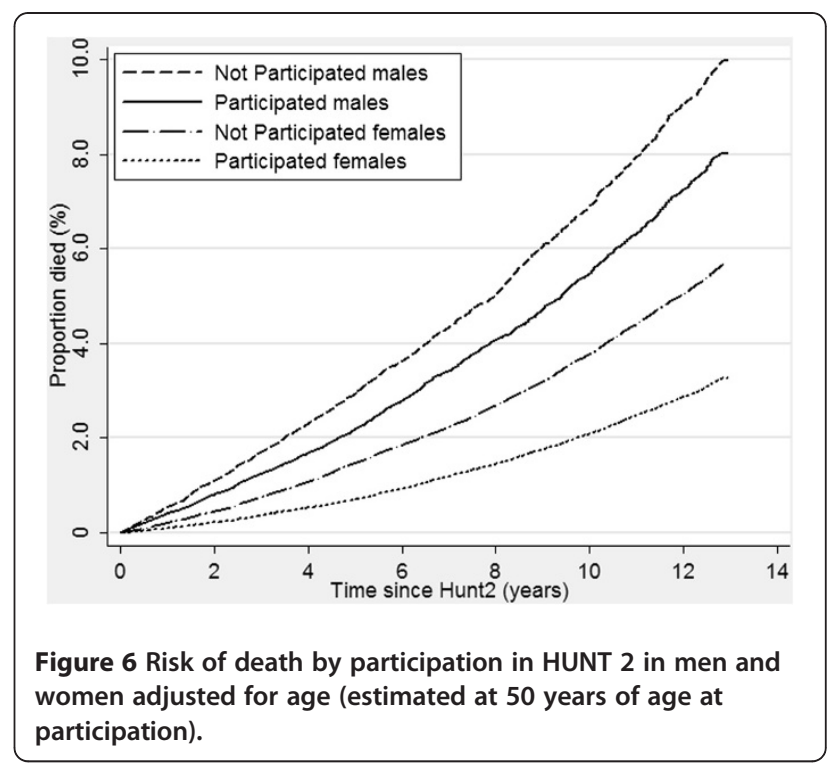

allowed by employers to meet during working time with full salary. To avoid nonparticipation due to the inconvenience of leaving work, the examination stations were open even in the early evenings. Participation was not stimulated by financial incentives, as previous studies have not found this to increase response rates [20].

There has been a general positive attitude towards health related research in the population of NordTrøndelag. Since HUNT2 (1995-97) there have been regular reports from HUNT-related research on the HUNT web-site and in the media. The HUNT Study has been supported by the Norwegian Parliament, the Government, the Ministry of Health, and there has been a close collaboration between the County Council, the municipalities and HUNT Research Centre.

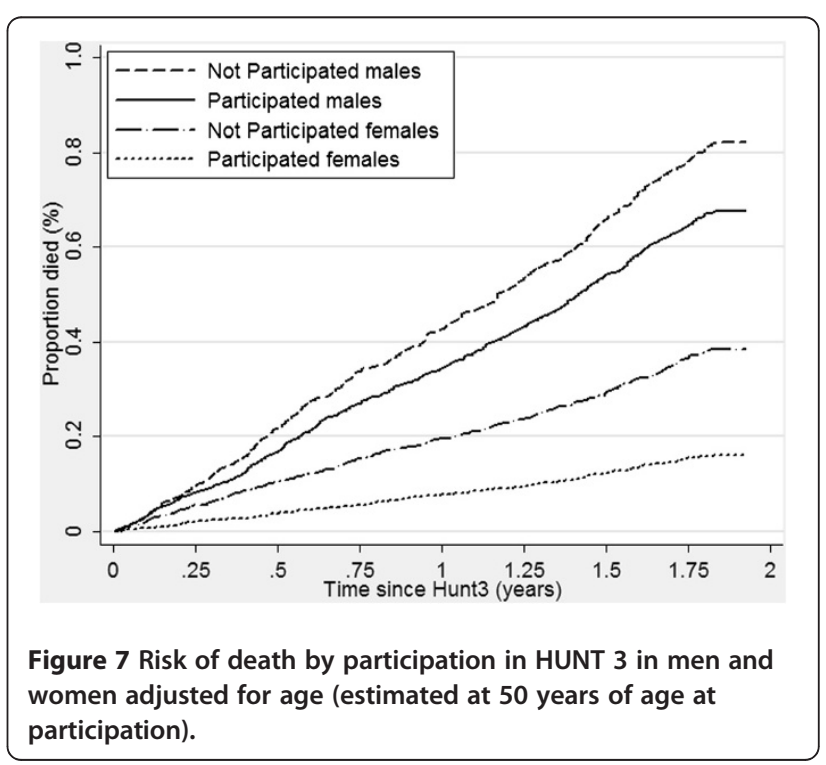


Additionally, the media have been strongly supportive of the HUNT Study.

\section{Influence on incidence and prevalence estimates}

Most studies have found little evidence for substantial bias due to nonparticipation [6,20,28-30]. In a Norwegian community respiratory cohort study, increasing the response rate from 65 to $89 \%$ after three reminders, resulted in no overt differences in incidence rates of respiratory symptoms and asthma as well as their associations to sex, age and smoking habits [31]. However, like the present study, others have reported underestimation of psychiatric disorders due to nonparticipation $[5,32,33]$. The scores of HADS anxiety and depression symptoms cannot be directly compared with GP's diagnosis of anxiety and depression. However, our finding of higher prevalence of reported anxiety symptoms compared to anxiety diagnosis, and lower prevalence of reported depressive symptoms compared to depression diagnosis, in participants compared to the background population, indicates that depression is a more restricting factor for participation than anxiety.

In line with other studies, nonparticipants in HUNT3 was also characterized by more unhealthy lifestyle regarding tobacco smoking and physical inactivity $[26,34]$, and poorer somatic status $[25,30,35,36]$. Data from the GPs further indicates as much as $50 \%$ higher prevalence of angina, myocardial infarction and stroke compared to the HUNT3 data, a pattern also found in other cardiovascular studies [25,35]. Correspondingly, the diabetes prevalence based on HUNT3 Q1 was underestimated both compared to QNP and the GP data based on diagnosis and prescription of medication. Higher prevalence indicated by GP diagnosis than by prescription data could be explained by prescription of insulin by hospital doctors for young adults, and attainment of adequate diabetic control by change in life style for many patients with diabetes type II.

The difference in BMI estimated by self-reported measures compared to measures at the examination stations in HUNT3 is in line with data from 2008 in an Australian study [37]. Lower participation rate among lower socioeconomic groups could contribute to reduce the difference between self-reported and measured anthropometrics.

\section{Influence on associations}

Many studies have found that subjects with risk behavior like smoking, high alcohol consumption or drug use are underrepresented in studies addressing these factors $[38,39]$. The corresponding pattern in the present study is mainly supposed to be related to differences in participation due to socioeconomic factors, as life style factors by themselves amounted to a small fraction of all questions. Studies on effects of environmental and occupational exposures have experienced participation bias depending on exposures measured [40,41]. By analyzing exposures in blood samples and linking HUNT data to external registers, a lot of associations can be analyzed, but these should not be influenced by participation as these topics have not been focused prior to the surveys.

Nonparticipation bias may be greater in surveys with higher participation rates compared with those with lower participation rates [34], as the differences between participants and nonparticipants may exaggerate real differences between participants and the eligible population sampled [25]. In the present study, however, inclusion of nonparticipants answering QNP increased the prevalence estimates for chronic diseases slightly, but this correction decreased the gap slightly in prevalence between the record data from general practice and HUNT participants. If we assume that the prevalences found among QNP participants 60 years and older, were representative of the entire nonparticipant group, the combined prevalences for the nonparticipants and Q1 participants would be close to the estimates found in the GP population for myocardial infarction and asthma, whilst for COPD, apoplexia and diabetes the GP population would still have higher prevalences. Strategies for improving participation rate should be developed and evaluated prior to the next HUNT survey. In this population increased participation rate seem to improve the external validity of prevalence estimates. After HUNT3 there has been a focus on overweight, obesity and laziness in the media. This might introduce differential influence on participation in future surveys due to stigmatization or victim blaming.

Nonparticipation has been found to be associated with two times higher risk of death independent of socioeconomic category in nonparticipants compared to participants, both in a 20 years follow-up study of white collar workers aged 35-55 years [42] and the FINRISK study, inviting persons aged 35-74 years [43]. Higher mortality risk among nonparticipants could be due to disabling diseases hindering study participation. To avoid inclusion of end stage patients in the present study, start of follow-up after each of the HUNT surveys were set to 2 (or two) months after study inclusion.

Strengths of this study were inclusion of several data sources for evaluation of nonparticipation bias, GP data representing background data regarding diagnoses and use of medication for the entire population, register data revealing potential nonparticipation bias by socioeconomic status and QNP reflecting the nonparticipation group. The representativeness of responders to QNP for the entire nonparticipation group might be questioned, but sensitivity tests for chronic diseases indicate that the validity of these data is rather good. 
Limitations of the study were inability to link data from general practices to HUNT-data due to patient confidentiality, use of registered diagnoses in general practices that could lead to some extent of underestimation of prevalence if doctors had not registered diagnoses given by previous GPs, and comparison of chronic diagnoses with symptom report for the last 12 months (for example head ache, urine incontinence). Background data from the GPs were collected three years after HUNT, but this should not introduce important bias in prevalence estimates.

Multiple testing may contribute to statistical significances by chance, but having this in mind, there seem to be consistent results on differences that researchers have to take into consideration.

\section{Conclusions}

A participation rate of $54 \%$ in HUNT3 was lower than expected, but for age groups 60-80 years the rates were $65 \%$ to $70 \%$. Compared to nonparticipation questionnaire and records from general practice, the prevalences, however, seem to be somewhat underestimated for chronic diseases already being treated in the health care. Higher prevalence among nonparticipants of cardiovascular diseases, diabetes and mental distress seem to parallel differences in socioeconomic groups and risk factor exposure. So far there is no reason to be concerned about introduction of bias in association and causal studies, but inclusion of a wide spectre of data and more sources for background data provide opportunity for addressing this in disease specific sensitivity studies.

\section{Additional files}

Additional file 1: Table S1. Comparisons of anthropometrics (means) and percentages reporting symptoms and diseases between participants having answered questionnaire 1 (Q1) (23 049) or questionnaire 2 (Q2), and those having answered a shortened nonparticipation questionnaire (QNP) ( $n=3677)$ among men stratified by age groups.

Additional file 2: Table S2. Comparisons of anthropometrics (means) and percentages reporting symptoms and diseases between participants having answered questionnaire 1 (Q1) (27 758) or questionnaire 2 (Q2), and those having answered a shortened nonparticipation questionnaire (QNP) $(n=3241)$ among women stratified by age groups.

\section{Competing interests}

The authors declare that they have no competing interests.

\section{Authors' contributions}

Langhammer A was the head of the questionnaire group in HUNT 3, and he is head of HUNT Databank. He planned the nonparticipation study, collected data, performed statistical analyses and drafted the manuscript. Krokstad S was the project leader of HUNT3, and he participated in planning, analyzes and commented on the manuscript. Romundstad P contributed in statistical analyses and commented on the manuscript. Heggland I was responsible for technical development of HUNT databank, contributed in data storage and quality assurance and commented on the manuscript. Holmen J was head of HUNT research Centre and the HUNT Study in 1984-2008, and he has commented on the manuscript.
Authors' information

None.

\section{Acknowledgments}

The Nord-Trøndelag Health Study (The HUNT Study) is collaboration between HUNT Research Centre (Faculty of Medicine, Norwegian University of Science and Technology NTNU), Nord-Trøndelag County Council, Central Norway Health Authority, and the Norwegian Institute of Public Health. We thank the selected general practices for contribution to GP data; Tangen Health Centre, Stjørdal, Ørmelen and Verdal Health Centres, Verdal, Inderøy Health Centre, Inderøy, Fyrgata and Høvdinggården Health Centres, Steinkjer, Snåsa Health Centre, Snåsa, and Robrygga Health Centre, Namsos.

\section{Author details}

'HUNT Research Centre, Department of Public Health and General Practice, Norwegian University of Science and Technology, Levanger, Norway. ${ }^{2}$ Department of Public Health and General Practice, Norwegian University of Science and Technology, Trondheim, Norway.

Received: 15 February 2012 Accepted: 29 August 2012

Published: 14 September 2012

\section{References}

1. Galea S, Tracy M: Participation rates in epidemiologic studies. Ann Epidemiol 2007, 17(9):643-653.

2. Holmen J, Midthjell K, Forsen L, Skjerve K, Gorseth M, Oseland A: A health survey in Nord-Trondelag 1984-86. Participation and comparison of attendants and non-attendants. Tidsskr Nor Laegeforen 1990, 110(15):1973-1977.

3. Holmen J, Midthjell K, Kruger O, Langhammer A, Holmen T, Bratberg GH, et al: The Nord-Trøndelag Health Study 1995-97 (HUNT2): objectives, contents, methods and participation. Norwegian Journal of Epidemiology 2003, 13(1):19-32. Available from: http://www.ntnu.no/c/document_library/ get_file?uuid=880d3372-dabc-404b-ba61-e1d27cb5bb09\&groupld=10304.

4. Krokstad S, Langhammer A, Hveem K, Holmen T, Midthjell K, Stene T, et al: Cohort profile: the HUNT Study, Norway. Int J Epidemiol 2012, Aug 9. [Epub ahead of print].

5. Knudsen AK, Hotopf M, Skogen JC, Overland S, Mykletun A: The health status of nonparticipants in a population-based health study: the Hordaland Health Study. Am J Epidemiol 2010, 172(11):1306-1314.

6. Sogaard AJ, Selmer R, Bjertness E, Thelle D: The Oslo Health Study: the impact of self-selection in a large, population-based survey. Int I Equity Health 2004, 3(1):3.

7. Langhammer A, Johnsen R, Holmen J, Gulsvik A, Bjermer L: Cigarette smoking gives more respiratory symptoms among women than among men. The Nord-Trondelag Health Study (HUNT). J Epidemiol Community Health 2000, 54(12):917-922.

8. National Institute of Public Health [database on the Internet]: National Institute of Public Health. Available from: http://www.norgeshelsa.no/ norgeshelsa/?language $=e$.

9. Norwegian Prescription Database [database on the Internet]: National Institute of Public Health. Available from: http://www.norpd.no/.

10. SSB: Statistics Norway. [database on the Internet]. http://www.ssb.no/en/.

11. Sogaard AJ, Bjelland E, Tell GS, Roysamb E: A comparison of the CONOR Mental Health Index to the HSCL-10 and HADS. Measuring mental health status in the Oslo Health Study and the Nord-Trøndelag Health Study. Norsk Epidemiol 2003, 13(2):279-284.

12. Zigmond AS, Snaith RP: The Hospital Anxiety and Depression Scale. Acta Psychiatr Scand 1983, 6:361-370.

13. Bjelland I, Dahl AA, Haug TT, Neckelmann D: The validity of the Hospital Anxiety and Depression Scale. An updated literature review. J Psychosom Res 2002, 52(2):69-77.

14. Jacobsen BK, Eggen AE, Mathiesen EB, Wilsgaard T, Njolstad I: Cohort profile: the Tromso Study. Int J Epidemiol 2012 Aug, 41(4):961-7.

15. Tambs K, Ronning T, Prescott CA, Kendler KS, Reichborn-Kjennerud T, Torgersen S, et al: The Norwegian Institute of Public Health Twin Study of Mental Health: examining recruitment and attrition bias. Twin Res Hum Genet 2009, 12(2):158-168.

16. MESA: MESA Exam 1 Participation Rate. MESA Coordinating Center. 2006 Available from: http://www.mesa-nhlbi.org/participation.aspx. 
17. BRFSS: Behavioral Risk Factor Surveillance System: 2005 Summary Data Quality Report. 2005. Available from: http://www.cdc.gov/brfss/technicalinfodata/ 2005QualityReport.htm.

18. Davis TC, Holcombe RF, Berkel HJ, Pramanik S, Divers SG: Informed consent for clinical trials: a comparative study of standard versus simplified forms. J Natl Cancer Inst 1998, 90(9):668-674.

19. Ross S, Grant A, Counsell C, Gillespie W, Russell I, Prescott R: Barriers to participation in randomised controlled trials: a systematic review. J Clin Epidemiol 1999, 52(12):1143-1156.

20. Asch DA, Jedrziewski MK, Christakis NA: Response rates to mail surveys published in medical journals. J Clin Epidemiol 1997, 50(10):1129-1136.

21. Jacobsen BK, Thelle DS: The Tromso Heart Study: responders and non-responders to a health questionnaire, do they differ? Scand I Soc Med 1988, 16(2):101-104.

22. Subar AF, Ziegler RG, Thompson FE, Johnson CC, Weissfeld JL, Reding D, et al: Is shorter always better? Relative importance of questionnaire length and cognitive ease on response rates and data quality for two dietary questionnaires. Am J Epidemiol 2001, 153(4):404-409.

23. Lund E, Dumeaux V, Braaten T, Hjartaker A, Engeset D, Skeie G, et al: Cohort profile: the Norwegian Women and Cancer Study-NOWAC-Kvinner og kreft. Int J Epidemiol 2008, 37(1):36-41.

24. Olson SH: Reported participation in case-control studies: changes over time. Am J Epidemiol 2001, 154(6):574-581.

25. Jackson R, Chambless LE, Yang K, Byrne T, Watson R, Folsom A, et al: Differences between respondents and nonrespondents in a multicenter community-based study vary by gender ethnicity. The Atherosclerosis Risk in Communities (ARIC) study investigators. J Clin Epidemiol 1996, 49(12):1441-1446.

26. Korkeila K, Suominen S, Ahvenainen J, Ojanlatva A, Rautava P, Helenius $\mathrm{H}$, et al: Non-response and related factors in a nation-wide health survey. Eur J Epidemiol 2001, 17(11):991-999.

27. Launer $L$, Wind AW, Deeg DJ: Nonresponse pattern and bias in a community-based cross-sectional study of cognitive functioning among the elderly. Am J Epidemiol 1994, 139(8):803-812.

28. Van Loon AJ, Tijhuis M, Picavet HS, Surtees PG, Ormel J: Survey non-response in the Netherlands: effects on prevalence estimates and associations. Ann Epidemiol 2003, 13(2):105-110.

29. Kreiger N, Nishri ED: The effect of nonresponse on estimation of relative risk in a case-control study. Ann Epidemiol 1997, 7(3):194-199.

30. Shahar E, Folsom AR, Jackson $R$ : The effect of nonresponse on prevalence estimates for a referent population: insights from a population-based cohort study. Atherosclerosis Risk in Communities (ARIC) study investigators. Ann Epidemiol 1996, 6(6):498-506.

31. Eagan TM, Eide GE, Gulsvik A, Bakke PS: Nonresponse in a community cohort study: predictors and consequences for exposure-disease associations. J Clin Epidemiol 2002, 55(8):775-781.

32. Hansen V, Jacobsen BK, Arnesen E: Prevalence of serious psychiatric morbidity in attenders and nonattenders to a health survey of a general population: the Tromso Health Study. Am J Epidemiol 2001, 154(10):891-894

33. Haapea M, Miettunen J, Laara E, Joukamaa MI, Jarvelin MR, Isohanni MK, et al: Non-participation in a field survey with respect to psychiatric disorders. Scand J Public Health 2008, 36(7):728-736.

34. Stang A: Nonresponse research-an underdeveloped field in epidemiology. Eur J Epidemiol 2003, 18(10):929-931.

35. Bisgard KM, Folsom AR, Hong CP, Sellers TA: Mortality and cancer rates in nonrespondents to a prospective study of older women: 5-year follow-up. Am J Epidemiol 1994, 139(10):990-1000.

36. Drivsholm T, Eplov LF, Davidsen M, Jorgensen T, Ibsen H, Hollnagel $H$, et al: Representativeness in population-based studies: a detailed description of non-response in a Danish cohort study. Scand J Public Health 2006, 34(6):623-631.

37. Hayes AJ, Clarke PM, Lung TW: Change in bias in self-reported body mass index in Australia between 1995 and 2008 and the evaluation of correction equations. Popul Health Metr 2011, 9:53.

38. Burg JA, Allred SL, Sapp JH: The potential for bias due to attrition in the national exposure registry: an examination of reasons for nonresponse, nonrespondent characteristics, and the response rate. Toxicol Ind Health 1997, 13(1):1-13.
39. Wild TC, Cunningham J, Adlaf E: Nonresponse in a follow-up to a representative telephone survey of adult drinkers. J Stud Alcohol 2001 62(2):257-261

40. Lahkola A, Salminen T, Auvinen A: Selection bias due to differential participation in a case-control study of mobile phone use and brain tumors. Ann Epidemiol 2005, 15(5):321-325.

41. Herr CE, Zur Nieden A, Jankofsky M, Stilianakis NI, Boedeker RH, Eikmann TF: Effects of bioaerosol polluted outdoor air on airways of residents: a cross sectional study. Occup Environ Med 2003, 60(5):336-342.

42. Ferrie JE, Kivimaki M, Singh-Manoux A, Shortt A, Martikainen P, Head J, et al: Non-response to baseline, non-response to follow-up and mortality in the Whitehall II cohort. Int J Epidemio/ 2009, 38(3):831-837

43. Harald K, Salomaa V, Jousilahti P, Koskinen S, Vartiainen E: Non-participation and mortality in different socioeconomic groups: the FINRISK population surveys in 1972-92. J Epidemiol Community Health 2007, 61(5):449-454.

doi:10.1186/1471-2288-12-143

Cite this article as: Langhammer et al:: The HUNT study: participation is associated with survival and depends on socioeconomic status, diseases and symptoms. BMC Medical Research Methodology 2012 12:143.

\section{Submit your next manuscript to BioMed Central and take full advantage of:}

- Convenient online submission

- Thorough peer review

- No space constraints or color figure charges

- Immediate publication on acceptance

- Inclusion in PubMed, CAS, Scopus and Google Scholar

- Research which is freely available for redistribution 